\title{
THE INTERNATIONAL EDUCATION AGENDA: INTERNATIONAL AND NEW ZEALAND WOMEN STUDENTS
}

\author{
Vivienne Anderson
}

\begin{abstract}
The International Education Agenda constructs internationalised education as central to New Zealand's economic transformation and strengthened sense of national identity. Its key outcomes for New Zealand students include their increased understanding and respect for 'other cultures'. The Agenda promises international students enrichment, support, and integration in New Zealand educational institutions and communities. In this paper I consider doctoral research interviews with international and New Zealand women students, to show how, while laudable, the Agenda's social aims may also be contradictory. Specifically, I discuss how national identity, if predicated on assumptions of New Zealanders' homogeneity, may preclude relations that are understanding and respectful, and how international students' enrichment and integration may be jeopardised by their concurrent positioning as a source of revenue. After highlighting how some women constructed New Zealand-ness and international-ness differently, I suggest some implications for international education policy and practice.
\end{abstract}

\section{INTRODUCTION}

The International Education Agenda: A Strategy for 2007-2012 [hereafter Agen$d a$ ] is a Ministry of Education (2007) policy document intended to set the direction for international education in New Zealand for the next five years. The goals that it articulates are organised under two 'overarching national priorities': 'economic transformation' and 'national identity' (Ministry of Education 2007: 8-9). The Agenda, like other international education documents during this decade, positions international education in market terms, both as a source of export revenue and of 'human capital' within the 'global [knowledge] economy' (Ministry of Education 2007: 2, 4, 9, 33). Simultaneously, its four key goals reveal an intertwining of social and economic aspirations: that 
New Zealand students be 'equipped to thrive in an interconnected world'; that international students be 'enriched by their education and living experiences in New Zealand'; that New Zealand educational institutions be 'financially and academically' strengthened through 'international linkages'; and that New Zealand receive 'wider social and economic benefits' (Ministry of Education 2007:9).

In this paper I am primarily concerned with the discursive construction of New Zealand-ness and international-ness that the Agenda reveals in its 'key outcomes' for New Zealand and international students (Ministry of Education 2007:9). For New Zealand students, promised outcomes include their increased 'global knowledge', 'understand[ing]' and 'respect' of 'other cultures', multicultural and multilingual skilfulness, and strengthened sense of national identity (Ministry of Education 2007:9). For international students promised outcomes include that they are welcomed and well-supported in New Zealand; academically successful; 'well integrated' within educational institutions, communities, and the (New Zealand) labour market; and that they 'become ongoing advocates' for New Zealand (Ministry of Education 2007:9-10). My contention in this paper is that while these outcomes are in some respects laudable, they may also be contradictory in two respects. First, a strengthened sense of 'identity as New Zealanders', if constructed in relation to homogeneity or sameness, may preclude relations that are 'understand [ing] and respect[ful]' (Ministry of Education 2007: 13). Second, international students' 'enrich[ment]' and 'integration into... our education institutions and communities' (Ministry of Education 2007:9) may be jeopardised by their concurrent positioning as a 'source of revenue' (2007: 28).

In the remainder of this paper I reflect on the aims of the Agenda in the light of doctoral research interviews with international and New Zealand women students living in a small New Zealand city. ${ }^{1}$ I begin by introducing Hall's (1996) notion of identity/identification as a basis for considering identities as slippery, not static, and discursively constructed, not natural. I relate Hall's ideas to examples from the Agenda in which New Zealanders are constructed as both diverse and homogenous, and international students are constructed as heterogeneous, culturally different others and/or a source of revenue. After introducing my own project, I then consider how women's interview accounts both revealed and contested a view of New Zealanders as homogenous, and of international students as racialised others and/or a source of export revenue. I discuss some alternative ways of imagining New Zealand-ness and international-ness that women's accounts suggest, and conclude with some implications for international education policy and practice. 
PROBLEMATISING 'IDENTITY'

Identities are in one sense 'naturally occurring ecologies' (Chawla and Rodriguez 2007:706) or how people identify with particular cultures or ways of being as a basis for belonging. Hall has argued that identities are also discursive; a process of articulating perceived commonalties and differences that are always 'an over-determination or a lack... never a proper fit, a totality' (1996:3). In this sense, even if used as if fixed and natural, identities are fundamentally unstable. They involve not just perceived differences but also the use of difference - in Hall's words, the 'binding and marking of symbolic boundaries' through the construction of 'a constitutive outside' (1996:3, also see Ang 2003).

While the Agenda espouses a strengthened sense of 'national identity' as a key priority for New Zealand students (Ministry of Education 2007: 9), it also reveals how (national) identity is slippery terrain. In places, it hints at the heterogeneity of New Zealanders, for example, suggesting that internationalised education may promote New Zealanders'

openness, interest, and positive attitude towards cultural differences... [thereby] empower[ing] students who do not have the opportunity to develop such attitudes at home, and...engag[ing $]$ students for whom cross-cultural navigation is a more frequent experience (Ministry of Education 2007: 13, citing Fernando Reimers, Ford Foundation Professor of International Education and Director of Global Education at Harvard Graduate School of Education, emphasis added).

Elsewhere, however, the Agenda identifies 'other cultures' as if outside New Zealand-ness (Ministry of Education 2007:13), and conflates (raced, cultured) other-ness with international-ness. For example, in an illustration of internationalisation in an intermediate school setting, the Agenda contrasts a 'typical New Zealand student eating their ham and salad roll' and 'a Korean pupil who might be eating their noodles or rice with chopsticks' (Ministry of Education 2007: 17, citing Madeleine East, Farm Cove School Principal). Although the school is described as including both Asian international students and Asian New Zealanders, Korean-ness is constructed as outside (typical) New Zealand-ness. Similarly, the Agenda deems 'cultural training' necessary for those 'teachers and staff dealing with international students' (Ministry of Education 2007: 21). Cultural diversity is constructed not as central to who 'we' are as New Zealanders, but as an issue that must be addressed in relation to the enrolment of (possibly culturally different) 'international' students. 
How the Agenda identifies international students is similarly contradictory. It explicitly acknowledges international students' heterogeneity:

There is huge diversity among international students in New Zealand.... While this document talks about 'international students' as a group, it is vital that providers, communities, and government recognise the diverse nature of this group, and their individual needs and aspirations (Ministry of Education 2007:18).

Meanwhile, it apparently conflates international-ness with cultural difference (see previous example) and constructs international students (not New Zealand students) as 'a source of revenue' (Ministry of Education 2007: 28). In this regard, while espousing the importance of international students 'feel[ing] part of our education institutions and communities' (Ministry of Education 2007: 18), the Agenda also clearly constructs them as other to New Zealand students.

\section{INTRODUCING THE PROJECT}

Doctoral research interviews conducted during 2005 and 2006 with international and New Zealand women students (like the Agenda) both revealed and contested a view of New Zealanders as homogenous, and international students as culturally different others and/or a source of export revenue. I consider their/our ${ }^{2}$ accounts here in order to draw explicit connections between discursive contradictions at policy level and human experiences and interactions in higher education (after Fine and Weis 2005). I also look for possibilities that the women's accounts suggest for constructing New Zealandness, international-ness, and 'internationalised' education differently.

The project took place in a small New Zealand city, and involved the development and evaluation of a social networking group for women who were international and New Zealand students, and partners of international students in public higher education institutions. The project was a response to ongoing concerns with the lack of interaction between international and New Zealand students (Ho, Li, Cooper, and Holmes 2007; Ward 2006; Ward and Masgoret 2004). It was also an attempt to explore similarities and dissimilarities in 'international' and 'New Zealand' women's perspectives and experiences, and the 'identity work' that shaped their interactions with and perceptions of each other (after Ichimoto 2004; Kenway and Bullen 2003). In addition, the project was an intentional response to the sidelining of gender in much international education literature (Bullen and Kenway 2003), and the invisibility of interna- 
tional students' partners and families in both international education policy and research (De Verthelyi 1995). ${ }^{3}$ The theoretical framework for the project was informed by critical feminist, poststructural, postcolonial and 'borderlands' perspectives. ${ }^{4}$

The group (Women Across Cultures) was established in conjunction with international office staff at a local university, and data was collected through participant observation and twenty-eight in-depth interviews with twenty women over two years. ${ }^{5}$ Interviewees were self-selected through the group and included eight international students (five full-fee paying students, one international doctoral student, ${ }^{6}$ and two exchange students), nine New Zealand students, and three women who were partners of international students. One New Zealand student and one international students' partner had previously studied in New Zealand as full-fee paying international students, and one international full-fee paying student had studied in New Zealand in both secondary and tertiary education contexts. These women reflected on both their current and earlier living and study experiences during our interviews. Of the New Zealand students interviewed, only three had been born and/or raised in New Zealand; the majority immigrated to New Zealand in the seven years prior to the project. Overall, eleven of the twenty interviewees had come to New Zealand either as immigrants, international students or partners of international students from countries in the Asian region.

Interviews followed a loose format based on a list of broad questions about the interviewees' previous and present living, study and/or occupational situations; their families; things that they enjoyed or found difficult in their current living, study and/or occupational roles; their involvement with and perspectives of Women Across Cultures and New Zealanders or international students; and their hopes and plans for the future. Interview questions were forwarded to the women prior to interviews and they adapted them as necessary, adding additional matters that they wished to discuss and indicating where they felt my questions were irrelevant. In this paper I focus specifically on two key themes that are useful for re-considering the Agenda as a national policy text and that emerged during interviews with all or some of the women: perceptions of $\mathrm{New}$ Zealand-ness and otherness, and the matter of fees and 'treatment'.

CONSTRUCTING, CONTESTING, AND ENCOUNTERING CONSTRUCTIONS OF 'NATIONAL IDENTITY'

Although, as Hall (1996) argues, identification is a discursive process that is slippery and unstable, particular identities may be more or less central to the 
functioning of a given social context, and as such, carry more or less discursive 'force' (also see Palumbo-Liu 2002). Nineteen of the twenty women that I interviewed constructed New Zealand-ness (or 'Kiwi'-ness) as an unmarked or sometimes, explicitly 'white' identification, and 'other' identifications (Chinese, Indian, Asian, Japanese, international, foreign, etc.) as marked categories or outside New Zealand-ness. These women included seven international and nine New Zealand students, and three women interviewed as international students' partners. That a homogenising and, at times, explicitly Anglocentric view of New Zealand-ness was revealed in women's interview accounts is hardly surprising, given that my interview questions were also peppered with international/local, us/them, New Zealander/other distinctions, and some of my questions elicited women's opinions specifically through the use of difference. ${ }^{7}$ Although the construction of New Zealand-ness as a homogenous, oppositional category to culturally different/international otherness was woven throughout our interviews, fifteen of the nineteen women (above) explicitly contested this. Women identified themselves and/or others as both inside and outside New Zealand-ness, while also challenging an inside/outside binary. When referring to particular identifications as if natural, women also problematised and resisted static and simplistic notions of nationhood, other-ness, and difference.

Three interview conversations are useful for illustrating both the ambiguities and the discursive force of a view of New Zealanders as homogenous and/ or 'white.' These were with Alexis (a Pakeha New Zealand student), Violet, and Sharon (international students from Malaysia and Taiwan respectively). These conversations were not exceptional or extraordinary, but I include them because of their clarity to reveal contradiction: both the use and contestation of forceful (homogenising) constructions of New Zealand-ness. As conversations with both New Zealand and international students, they also revealed interesting parallels and differences.

Alexis, a first-generation New Zealander whose parents had immigrated to New Zealand from Western Europe, was explicitly critical of New Zealanders identifying 'international people' as unwanted outsiders:

New Zealand is very conservative, not well-travelled, not used to different cultures... Every week, somebody makes a comment to me about...international people.... You know 'taking our jobs', 'taking over', 'eating weird things' (interview $1 / 2,2005){ }^{8}$

While contesting New Zealanders' 'conservati[sm]', Alexis also mirrored the 
Agenda's conflation of international-ness/otherness/difference. Later in the interview Alexis's use of difference in relation to some 'others' was more explicit. Here she reflects on interactions between New Zealand and international students on campus:

I know that there are certain countries that are groovier than others, like I can see that Japanese students are slightly groovier than Chinese in the way they dress... and probably are better at interacting with Kiwi students, and poor old Chinese students, they are lovely but they are so different.

Alexis positioned both Japanese-ness and Chinese-ness as to a greater or lesser extent outside New Zealand-ness, and (in contrast with her earlier portrayal of New Zealanders' intercultural ineptness), as more or less adept at social interaction. In particular, Alexis positioned Chinese students as 'so different' - objects of pity that lack both (acceptable) dress sense and skilfulness in social interaction. New Zealanders on the other hand, remained an unmarked (well-dressed?) 'same'.

Violet and Sharon also used marked and unmarked categories to distinguish between New Zealanders and others, but for them, 'white' New Zealand-ness functioned as an imagined 'ideal' (Hall 1996:2). Both women described meeting 'Kiwi people' as a central motivation in coming to New Zealand, and a lack of 'Kiwi friends' as a source of disappointment and frustration. First Violet:

I mean coming all the way from Malaysia... one of the things is... you really want to meet Kiwi people, get into their culture or something. And... you find here... it's not that easy to get into... these people's group (international FFPS from Malaysia, interview 1/2, 2005).

And Sharon:

Before I came here the information I can get is all from the TV series, the movies.... It was 'Wow it's so cool to study in the foreign school and then you will hang out with... the [local] people there.' But it's totally different (international excs from Taiwan, interview $1 / 1,2005)$.

Elsewhere in their accounts, Sharon and Violet revealed more explicitly how they imagined New Zealand-ness. Here Violet expresses her dismay when the 
New Zealanders she was matched with in a local hospitality programme did not match her idealised notion of New Zealand-ness:

They advertise it as... we'll get you into like a Kiwi friend or family... but this Kiwi is not the kind of Kiwi that we are thinking. What we are thinking is like, they are born here... maybe a few generations here. But... the Kiwi that they [matched us with] is those that have a PR... ${ }^{9}$ all the Kiwi that there is is like Chinese Thai... Singapore Chinese... Indonesian Chinese. It was like... all the Chinese!

For Violet, Chinese, Singaporean, Indonesian and Thai New Zealanders did not qualify as (desirable) 'Kiwi' friends, whether because of their ethnicity or their 'new-ness' to New Zealand. Similarly, Sharon positioned Asian-ness outside New Zealand-ness, describing the 'very obvious' separation between 'Asian' and 'New Zealand' students in her Hall of Residence as a 'natural' consequence of students' similar/different experiences, shared/disparate backgrounds and experiences of being local/international:

I still hang out with Asian people more, like in the students' hall... probably it's because $[o f]$ the cultures or... it's easier to... get along or to talk to the Asian people where you think they look quite similar to you with the yellow skin, black hair or... you have the similar background, like... international students here.

When I asked Sharon if any of her Asian friends were New Zealanders, she admitted that some of her friends were 'Kiwi-born Asians' or 'Kiwi-born Chinese'. In contrast with her earlier statement, Sharon did have New Zealand friends, but like Violet, she considered them not to be 'really... Kiwi friends'.

The Agenda constructs internationalised education as fostering New Zealanders' strengthened sense of national identity as well as their multicultural and multilingual skilfulness, and ability to be open to others. Five women highlighted how a sense of national identity, if exclusive or predicated on assumptions of New Zealanders' sameness, might equally foster suspicion and exclusion of some international students and New Zealanders. For these women, the conflation of international-ness with racialised other-ness and New Zealand-ness with homogeneity or 'white-ness' was played out, not just at a discursive level, but also at times through day-to-day erasure, hostility and physical harassment. Stella, Yukiko, and Frances described such encounters using the words 'racism' and 'discrimination'. Roja and Rose did not use these words, but described the encounters and their feelings in response. Stella, 
Yukiko and Roja explicitly linked their negative encounters with their visible 'other-ness' in New Zealand, whereas Frances drew a connection between New Zealand-ness and 'whiteness' elsewhere in the interview so that the link was implicit rather than explicit. Rose, who looked 'white', linked the harassment she experienced with her appearance as 'Muslim. ${ }^{10}$ In all five cases, the link between negative treatment and being positioned as marked outsiders or different to 'white'/Anglo New Zealand-ness was unmistakably clear.

\section{Erasure}

Roja, Stella, and Yukiko described occasions in New Zealand when they experienced being 'first seen (racialised)' by (other) New Zealanders, 'and then not seen (ignored)' (Diangelo 2006:1993). Roja, who had initially come to New Zealand as a full-fee paying international student from India, suspected that her marked difference in New Zealand contributed to her inability to gain employment after graduating. She expressed frustration at the impossibility of proving this suspicion, recalling the denial that she had encountered from a 'white' woman present when she attempted to raise the issue at a local council meeting. ${ }^{11}$ Stella, who had migrated from South Korea to New Zealand, described how she was often ignored by shop assistants and other service workers. While noting that this 'rudeness' could simply be indicative of a person's 'bad day', she suggested that it indicated 'racism', noting the marked contrast between their response to her, and her 'European' husband:

Wherever we go the service people... doesn't treat me as the same as [my husband]... Sometimes when we walk in the shop... I ask some questions first, then the people answer to [my husband], not looking at me.... Very many, many, many times happened (interview $2 / 2,2006)$.

In contrast with the Agenda's goals for international students (enrichment, welcome, integration), Yukiko, an international full-fee paying student from Japan, alluded to her experience of being treated as if invisible by New Zealand students during her two years in a New Zealand high school. She also recalled a fellow Japanese international student's description of being treated 'like air' by 'white' New Zealand students in a tertiary classroom. Like Roja, Yukiko highlighted how exclusion through erasure is doubly forceful: both clearly evident and easily denied (see Doane 2006). Her statement, 'New Zealanders would not think they are... racist', juxtaposed sharply against, 'We sometimes really get hurt.... I am pretty sure many, the majority of international students' (interview 2/2, 2006). 


\section{Harassment/Abuse}

Rose, Frances, Yukiko, and Stella were sometimes identified as outsiders to New Zealand-ness through clearly targeted verbal and/or physical abuse. All four women provided examples of what Collins (2006:230) calls 'discursive violence' - occasions when they were forcibly excluded from belonging in New Zealand (in Stella's case, despite being a New Zealand student). Rose, an international student's partner and former full-fee paying student from South-west Asia, recalled three separate occasions when passing young people had called her names such as 'sister of Bin Laden'. Frances, an international exchange student from China, was told by drunken students, to 'go back to China, and Yukiko was sworn at by New Zealand students in her tertiary institution. Like Rose, both Frances and Yukiko described such exchanges as occurring multiple times. Stella also described an occasion when her marked positionality in New Zealand was clearly articulated by a young woman on her city's main street:

We were walking, and there were a bunch of young people in the car and... one girl shouted something... she was pointing at some direction and was saying 'airport is that way'. And the moment I just understood what happened... it was like 'Oh my god, what am I doing in this country... why did I come here?' It was so sad (interview $2 / 2,2006)$.

Although a New Zealand student and permanent resident, on this occasion, Stella was identified as a marked outsider who did not belong in the 'nation'.

Rose and Yukiko recalled occasions when they and fellow international students had encountered racially-targeted violence that was not just discursive but physical. Both women described having water thrown at them, and Yukiko discussed how New Zealand students at senior secondary school had regularly kicked and tripped Japanese international students. Yukiko also described an occasion when New Zealand students had approached and spat in her (Japanese) friend's face. For Roja, Stella, Yukiko, Rose, and Frances, others' strong sense of 'national identity' (Ministry of Education 2007:9) was not experienced as 'openness, interest, and a positive attitude towards... differences'(2007:13), but through erasure, exclusion and harassment.

BEING CONSTRUCTED AS A SOURCE OF REVENUE

As Haigh (2002:50) argues and the Agenda reveals, international students are 
'big business', but clearly, within an 'export education industry' (Ministry of Education 2007:2), full-fee paying international students are bigger business than others. In my study, five of the seven women who were or had earlier been full-fee paying international students ${ }^{12}$ described a sense of being constructed as a source of revenue within an education 'marketplace', of actively constructing themselves as consumers or a source of revenue while studying in New Zealand, or of resisting being constructed in this way. The only other student who referred to being constructed as a source of revenue was Stella, a New Zealand student. Stella spoke about being (wrongly) identified by others as a full-fee paying international student by virtue of her Asian-ness, and therefore as a source of institutional revenue.

Fiona, Rose and Nikki spoke with frustration about institutional practices that reinforced their positioning as a source of revenue within educational institutions. At the same time, these women were not simply victims of 'market' discourses or of institutional power, since each had freely chosen to study in New Zealand, desiring particular educational 'goods' for their own personal and professional benefit. Both Fiona and Rose, also actively confronted institutional staff over the matter of fees, but Nikki, who decided that her tertiary study in New Zealand was not 'worth it', withdrew from her course of study. Although at times during our interviews all three women rejected a 'market' view of education outright, at other times, they did so by simultaneously taking up a 'consumer' identity; acting or speaking as paying customers 'within/ against' institutional practices (Lather 2006: 41).

Fiona, a full-fee paying international student from Canada, referred to being constructed as a source of revenue in her son's primary school. As a full-fee paying international student and the mother of a school-aged child, she was required to pay full international fees for both her own and her son's studies. Fiona described an occasion when she received an angry letter from her son's school principal after having missed a fee payment deadline by one day. Since prior to this occasion, Fiona had consistently paid her son's fees on time and without question, she was surprised and upset by the tone of the letter. On the same day, she also received an additional letter requesting a further $\$ 100$ for school 'activity fees' and stationery. Here Fiona recalls the conversation with the school principal in which she demanded an explanation concerning both his letters, and the use of her son's tuition fees:

[Recalling the principal's response] First he was like, 'Well about the letter... by not paying this you're asking us to break the law... it's illegal to have [child's name] in school if he hasn't paid his tuition up to 
date.... And then I got pretty angry and I said, ... 'Well, how much does it cost... to have one New Zealander in school?' I said, 'We're paying $\$ 8,500$, that's just an insane amount!'... and the principal of the school looked at me... he's been a principal for many years... so he should know how much it costs to have a New Zealander in school, and he looked at me straight in the eye and said he didn't know, that this was... not part of his job, and I just... 'What do you mean you don't know?!'...And then he said to me, 'Okay well, I'll tell you what, you don't have to pay the extra hundred dollars' (interview $1 / 1,2005)$.

Ironically, while evidently contesting the marketisation of her son's primary school education, Fiona might also be read as simultaneously performing a 'consumer' identity. Fiona expressed anger at the principal's apparent lack of knowledge about the education 'industry' in which he was a participating actor, and refusing to see the marketisation of education as a 'process without a subject or agent' (Robertson 2006:305), insisted on holding him accountable. As such, she was able to exercise some power causing the principal to drop his request for additional fees. Fiona found this achievement no cause for celebration, however, but (like the school principal) expressed unease about her positioning within the 'export education industry' (Ministry of Education 2007: 2). She commented ruefully, 'I just kind of left feeling like I was a money machine and actually I should have a right to make the rules practically at the school 'cause I pay so much!'

Rose, who, like Fiona, contested her (former) university's attempt to charge extra fees, highlighted the barriers that may prevent some students from laying formal complaints about unscrupulous or substandard 'industry' dealings. An experienced professional in her 'home' country, Rose was surprised when she arrived at her university to be confronted with a request for $\$ 10,000$ in excess of the $\$ 17,000$ indicated on pre-arrival information. When Rose asked the university fees office why she was being asked to pay additional fees, staff insisted that she had misunderstood the pre-arrival information. Rose resisted this explanation and refused to pay the additional fees until she had sought advice from embassy staff, who then consulted a lawyer on her behalf. At this stage, Rose was living apart from close family support, had already paid large sums of money for accommodation and airfares, and was now behind in assessment tasks due to the delay in her enrolment. Although advised that she had legal grounds for laying a formal complaint, Rose decided that doing so was not worthwhile. She told me that, in part, this was because she was 'already stressed', and in part, because she felt that as a government employee 
in her home country, pursuing a formal complaint against a New Zealand educational institution was inappropriate.

Despite her decision not to initiate a grievance process, Rose's initial refusal to pay additional fees was (like Fiona's) partially effective. Following contact from the embassy, staff at Rose's university agreed to offer Rose a \$4,000 scholarship if she would pay the outstanding amount. Rose agreed, relieved to finally enrol and commence coursework, but she read the university's 'generosity' as a covert admission of guilt, saying, 'They know that they're wrong because they... offered me this scholarship.... They knew that I showed it to the lawyer'.

Like Fiona, while disliking the need to do so, Rose recognised the necessity as a full-fee paying international student of being an informed 'consumer'. When I asked what advice she would give a prospective international student, Rose replied:

Know more about the institute, and especially the paper work, and understand well before accepting anything.... Have the receipts, and everything, because ... they want to make [out that] the student is wrong.... My advice is to keep everything, and... to seek for help always (interview $1 / 1,2006$ ).

Rose hinted, however, at the unsustainability of a money-driven approach to the provision of education, citing the anger of embassy staff in her own case and describing how two other students from her country had already withdrawn their enrolment and spent their study dollars elsewhere. It is ironic that for Rose's university, an emphasis on revenue generation may have been selfdefeating. Neither Rose nor the embassy personnel who supported her were likely to act as 'ongoing advocates for New Zealand' or for the New Zealand university that Rose attended (Ministry of Education 2007: 18).

Unlike Rose, who had come to New Zealand primarily for professional reasons, Nikki, an international full-fee paying student from Norway chose to study abroad in order to '[experience] New Zealand' with her partner and young child. In reality, however, Nikki found coursework and juggling study and domestic commitments much more demanding than she had expected, and her goal of 'experiencing New Zealand' incompatible with continuing her studies. When I interviewed her, Nikki had already decided to withdraw at the end of her first semester. I knew at this stage that Nikki was pregnant with her second child, and when I asked if her withdrawal was in some way related to this pregnancy, she replied: 
No because it's such a lot of money and I would probably have failed. I don't want to waste that much money and just be at university and not seeing my family and not seeing New Zealand. So yeah I think I would have quit anyway (interview 1/1, 2005).

Nikki expressed frustration at the ways in which international education marketing campaigns capitalise on international students' desire to experience New Zealand for the express purpose of promoting the sale of an (international) education (for example, see Education New Zealand 2008). She argued that for her, and arguably for other international students, an image of 'internationalised' education as an opportunity to have a good time is both highly attractive and inaccurate:

I think that all the commercial about come and... have a good time and I don't think people have time to do that when they study, like all the partying and going places and stuff it's not if you're an international student... because then it's more than enough just to try to understand everything the lecturers say.

Nikki highlighted how a 'coordinated approach to promotion and marketing by education providers' (Ministry of Education 2007:26) is problematic if it effectively promotes a false or simplistic image of studying in New Zealand, or one likely to fuel unrealistic expectations for some students.

Like Fiona, Nikki rejected a 'market' approach to education outright, saying, 'I think it's really stupid that international students have to pay so much... because then only a limited amount of people can actually go abroad'. She also, however, exercised her 'consumer' judgment in declaring a New Zealand education 'not worth it' (see earlier). Nikki's account, when considered alongside Rose's, highlights how politico-economic factors intersect to position full-fee paying students differently. Whatever she chose to do in New Zealand, Nikki was well-supported by her 'home' government. In contrast, Rose felt her options were limited, partly due to her role as a government employee, and partly due to the economic and personal sacrifices already made for her to be here. Nikki had come to New Zealand in order to experience the country, and while study pressures jeopardised this possibility, withdrawal from study did not. In contrast, Rose had come here specifically in order to obtain a New Zealand qualification. As such, withdrawal was for her, not an option. 
Three women (Yukiko, Roja, and Stella) referred to a sense of contradiction - being dually constructed in New Zealand educational contexts as both a (valued) source of revenue and (unwanted) outsiders (see Collins 2006). Yukiko and Roja spoke of a disjuncture between the fees that they paid (as a full-fee paying international student and a former full-fee paying student, respectively), and the 'treatment' that they experienced in a high school context (Yukiko) and when trying to get work (Roja). Stella described encountering other New Zealanders' assumptions in her university context in which her 'Asian-ness' was wrongly read as indicative of her enrolment status as a full-fee paying international student.

Like Nikki, Yukiko reflected on New Zealand's marketing strategies, recalling having chosen a secondary school in New Zealand on the basis of a marketing brochure that projected a caring, inclusive image of the school. In contrast, upon her arrival Yukiko found that international and New Zealand students at the school rarely mixed, and that international students were regularly subjected to harassment and bullying (see earlier). In the statement below, Yukiko does not contest having to pay fees per se, but rather the mismatch between the fees her parents were paying and the reception that she received in the school. She said:

When I found out I'm paying 9,ooo per year... for the... tuition fees at the... high school, and when I found out... that these local students pays only 75 dollars... I just felt so shocked.... I could not describe why... the fees and also the treatment... we get here... it's just so... doesn't match (interview 1/2, 2005).

In addition to a mismatch between fees and 'treatment', like Fiona, Yukiko also noted a lack of transparency around the use of international students' fees at both institutional and national levels. Referring now to higher education, Yukiko noted the irony that while international student supports were apparently allocated a low level of funding and afforded low visibility, her university was evidently able to purchase many showy and unnecessary 'extras':

I still want to know the truth-how much actually government is getting the benefit from us, and [the university] too.... There are lots of things that are unnecessary... like, for example in the library there [are] seven... thin TV things hanging on the top floor... that cost... three thousand or... five thousand... one TV, and yet that is not 
really doing much! It's even turned off now! You know it's black! [laughing] And... is it... coming from our... money? Then I would be really sad actually.

Roja also noted her ambivalent positioning as an unwanted outsider and a 'valued' source of revenue in New Zealand. She contrasted the eagerness with which educational institutions market themselves to and enrol full-fee paying international students with the reluctance of New Zealand employers to give her a job once she had graduated and gained Permanent Residency. Despite having paid full-fees to gain a New Zealand degree in a 'skill-shortage' area (see Immigration New Zealand 2007), Roja did not find herself positioned as 'talent in a tight labour market' (Ministry of Education 2007:21), but as apparently unemployable:

When I ring up I ask people, 'Why don't you... consider?', so example... I rang up and just a call-centre thing... and I think accent became a problem. First when I spoke with them he said, 'You are kind of over-qualified, would you do this kind of job?' And I said, 'I... love to work! I want to, I don't mind. It's still computing...., and then I didn't get the interview... I got the explanation saying that there were more skilled people there, and I was comparing these two (interview 1/1, 2006).

As noted earlier, Roja suspected that her inability to get a job was in part, a result of others' identification of her as an (incompetent) outsider. When I interviewed her, she was completing postgraduate study, this time as a New Zealand student. Roja's return to study was clearly not a result of having been 'enriched' by her earlier study experiences (Ministry of Education 2007: 18), but rather, as she put it, a preferable option to 'sitting at home'.

Stella described the slippage of some international students' contradictory (wanted/ unwanted) positioning to her as a Korean New Zealander:

When I met people on the campus.... the perception they have of me... is... I'm an Asian, they think I'm young international student, therefore you've got money.... And you study science or commerce... that's the whole concept they get from me, even though I don't say a word.... But if you talk for about one or two minutes they realise that I'm not in that category... they don't see me as an individual person, but they just start... thinking of me because of my appearance, so... I think that has to be changed. Obviously, ok, I'm an 
Asian but I'm not an international student which means I don't have that much money [laughing], and I'm a [New Zealand] student who is married (interview 2/2, 2006).

Although not a full-fee paying international student, Stella, like Roja, expressed annoyance at how in interactions with some New Zealanders, her 'identity [was often] produced well in advance of the interpersonal encounter' (Palumbo-Liu 2002: 767). This occurred through others' conflation of Asian-ness, foreign-ness, and wealth (see Collins 2006). Stella expressed frustration at being constructed alongside predominantly Asian full-fee paying international students as young, wealthy, and a 'constitutive outside' to New Zealand-ness (Hall 1996:3).

DESTABILISING STATIC NOTIONS OF DIFFERENCE, INTERNATIONAL-NESS, AND NEW ZEALAND-NESS

Having discussed the discursive and material implications of a static notion of national identity and of international students as culturally different others and/or a source of revenue, I turn now to moments in which women identified themselves and others differently. Five women in my study described being marked as 'different' in New Zealand not only in relation to pain, frustration or a sense of being dominated, but also as a condition of possibility (Brooks 2004). For Frances and Miho, international students from China and Japan, respectively, being 'different' was in some respects freeing - a release from family expectations and obligations. Here Frances explains her 'different-ness' as allowing an opportunity for re-invention and self-discovery:

In China... you are familiar with the environment and you are familiar with all the people. So like sometimes you... go in the same ways as them, even if you don't know whether that's the way you want to be. Whereas if you [are] in a totally different environment, no one knows you... so you don't need to care about [how] other people see you, observe how you act, so you can do whatever you like, with total freedom (international Excs from China, interview $1 / 1,2006)$.

Miho noted two other ways in which she enjoyed being a 'foreigner' in New Zealand: first, because she found shared foreign-ness to be a point of commonality with others and a basis for new friendships; and second, because her Japanese-ness attracted the interest of New Zealanders interested in Japan. Miho stated that by studying in New Zealand she had ' $[$ got $]$ to know about 
Asian cultures more' (international fFPs from Japan, interview 1/1, 2005). At the same time, Miho also expressed irritation at how New Zealanders often homogenised 'Asian-ness'.

Some women's accounts offered alternative ways of constructing selves and others in internationalised education: either inverting us/them, local/international, New Zealander/other, same/different distinctions; or destabilising them altogether. For example, three women positioned New Zealand-ness in terms of a 'lack'. Deanna, an international doctoral student from Switzerland, suggested that 'a lot of Kiwis... are ignorant about language' (interview 2/2, 2006). Yukiko described New Zealanders as careless and recalled a friend's more disparaging description: 'Kiwis are really country people.... They are like animals, they walk with no shoes, you know barefoot [laughter], so dirty' (interview 2/2, 2006). Violet suggested that some New Zealanders' 'carelessness' might be related to the fact that they have never experienced being 'foreign'. Alluding to the lack of (non-Asian) New Zealanders involved in the hospitality programme discussed earlier, she said: 'It's hard to really get the Kiwi who have no experience to do this sort of work, because they don't see the need' (interview $1 / 2,2005$ ).

Arui, Violet, and Yukiko, spoke of their 'outside-ness' in New Zealand as fostering new insights and necessary creativity (see Lugones 1987). Arui, a New Zealand student from China, for example, described how she learned to rationalise some New Zealanders' 'coolness' towards her in terms of their 'busy[ness]'. When I asked what advice she would give another newcomer to New Zealand, she highlighted the importance of clinging to positive explanations as an active coping strategy. She said, 'Never give up. Always have best hope. Always be nice to others.... Always believe everybody's nice to you' (interview 1/1, 2006). Likewise, Violet likened some New Zealanders' 'inexperience' to her own previous inexperience of being foreign, revealing how her attitude towards foreigners had changed through experiencing foreign-ness herself:

After I go through all this thing I see the need, and maybe... there's someone when I go back to Malaysia and someone need some help I'll be really glad to help you know, but before I experienced I was like, 'You choose to come here... you should be alright!' (interview $1 / 2,2005)$.

Yukiko learned to recognise some New Zealand students' disinterest or hostility as indicating their 'fear' of her unfamiliarity. This allowed her to mentally disrupt the social segregation between New Zealand students and Japanese 
international students: 'They got scared of course, they just hid[ing] their fear... so the same as us, yeah, same as me I guess' (interview 1/2, 2005). Yukiko described a technique for building friendships with New Zealand students that she had developed as a result of her new insights:

This is how I actually established friendships with some of New Zealand students.... I attack them when they are one [laughs]!... They cannot ignore it. They cannot make an excuse.... I just see them, they're sitting... just by themselves. Attack them now! [laughter]... In this way I really made lots of valuable friendships (interview 2/2, 2006).

She suggested that teaching exchange opportunities might offer opportunities for New Zealand staff to similarly learn to see themselves and others differently.

In seeking to reconsider the Agenda in the light of international and New Zealand women students' accounts I am faced with a dilemma. On one hand, by highlighting the discursive and material implications of exclusive notions of nationhood and a preoccupation with 'market' concerns in internationalised education, I risk re-inscribing a view of some people as outsiders to New Zealand-ness and/or reifying 'market' concerns (see Larner 2003; Robertson 2006). On the other hand, to downplay or minimalise the real consequences of identifying people in relation to racialising or commodifying assumptions is ethically untenable, given the human pain (and ironically, vast sums of money) involved (Haigh 2002). It is simplistic to represent the women in this paper simply as 'victims' or 'resistors' of international education policies and practices. Each spoke from multiple positions: sometimes as outsiders or insiders to nationhood; sometimes as multilingual, critical, and well-informed actors or resistors in the international education 'marketplace'; and other times, as targets of racialising, commodifying assumptions and unscrupulous institutional practices.

What is significant in terms of the Agenda, is the way in which for some women, being constructed in New Zealand as marked outsiders and/or a source of revenue reinforced us/them, New Zealand/international divisions, producing suspicion, caution, erasure, harassment, and deep frustration. Ironically, the open-ness to others and understanding promised in the Agenda's key outcomes for New Zealand students characterised women's necessarily creative 
responses to being marked as (unwanted) outsiders and/or sources of revenue (see previous section). The data in this chapter suggests that while laudable, the Agenda's emphasis on fostering uderstanding, respect, and connection between people through internationalised education may be at odds with its construction of internationalised education as a forum for fostering both a strengthened sense of 'national identity' and 'economic transformation' (see Ministry of Education 2007: 9). National identity, if predicated on sameness or homogeneity, rests on the construction of a 'constitutive outside' (Hall 1996:3); and economic transformation through education rests in part on the construction of some students in terms of their dollar value. As Ippolito (2007:752) has noted, and this paper has shown, us/them 'separation at policy level' risks being 'translated directly into practice, challenging integration, interaction and intercultural learning'.

Although this study was limited in its size and scope and involved only female students, it nevertheless suggests some implications for international education policy and practice. The first is the importance of remaining open to 'the possibility of commonalties and differences at all times' (Madge, Raghuram and Noxolo 2008:13) - that is, recognising at all levels the instability of ' $\mathrm{New}$ Zealand-ness' and 'international-ness', and fostering a sense of national identity that is not fixed but open to multiplicity, differentiation and change. This may be through policy that recognises cultural diversity as integral to both national and 'internationalised' teaching and learning contexts, and affirms multicultural and multilingual skilfulness as central to good pedagogy rather than an 'add-on' for staff responsible for 'dealing with international students' (Ministry of Education 2007:21). Also, the importance of emphasising pedagogical and support responsibilities over marketing, branding, or financial concerns cannot be overstated. For some of the women in this paper, being positioned as a source of revenue resulted in a completely different set of social outcomes than those the Agenda espouses: for example, the taking up of 'consumer' identities, the undermining of the 'New Zealand-educated' brand (Ministry of Education 2007:36), and social separation between people. At the very least, Rose's account highlights the importance of access to independent advocacy and assistance in contexts where full-fee paying international students are enrolled as a source of export earnings; and Yukiko's and Nikki's accounts highlight the importance of frank and full information rather than the projection of marketable images.

Notably, Arui, Violet and Yukikos' creative survival strategies offer some insights into a way forward. They suggest that an ability to disrupt us/them distinctions and build interpersonal/intercultural connection relies at least in part 
on a learned open-ness to 'the possibility of commonalties and differences' between people without prejudging either (see Madge et al 2008:13). Yukiko suggested that exchange opportunities for staff might be a way of fostering such learning. How exchange might be fostered within New Zealand educational contexts in such as way as to destabilise static notions of self and other (or 'local' and 'international'), is a crucial question for both research and policy.

\section{NOTES}

1 The terms 'New Zealand' and 'international' refer to students' enrolment categories when interviewed. My purpose in writing this paper is in part to problematise the straightforward use of these terms, and the us/them distinction that they suggest.

2 I include myself here, since as interviewer (and a New Zealand student) I was implicated in the discursive constructions of selves and others that emerged in interview data.

3 Although this paper does not address gender-related issues as a specific concern, by foregrounding the voices of women students it counters the gender-neutrality or normalisation of maleness that characterises much international education literature (see Bullen and Kenway 2003).

4 A full description of each of these is beyond the scope of this paper, but in brief, the project was concerned with the connections and disconnections between women's complex subjectivities (Brooks 2004), the politico-historical context in which they lived and studied, and their experiences of shifting between and across social and educational 'worlds' (after Fine and Weis 2005).

5 Eight women were interviewed twice.

6 Since April 2005, international doctoral students have been able to enrol as 'domestic students' for fees purposes (Ministry of Education 2008).

7 For example, 'what experiences have you had interacting with international students or people from countries other than New Zealand?' and 'has your involvement in Women Across Cultures influenced how you think about New Zealanders?'

8 When quoting interviews, bold type indicates where interviewees emphasised particular words or phrases and ellipsis indicate a pause in the conversation or 
an omission to protect an interviewee's anonymity. Following the first excerpt from each interview I indicate the interviewee's enrolment status, and the interview number and year. 'FFPs' is short for full-fee paying student and 'ExCs' for exchange student. The first number indicates which interview the excerpt came from and the second, how many interviews I had with the interviewee in total. Where I include subsequent quotes from the same interviewee, I include interview number/date information only if the excerpt was from a different interview to that cited earlier. All interview transcripts were checked by interviewees prior to publication.

9 Permanent Residency visa status.

10 Specifically her use of a hijab (head scarf).

11 Notably, the Agenda acknowledges that employer attitudes may be a factor limiting job opportunities for both international graduates and skilled migrants in New Zealand (see Ministry of Education 2007: 20).

12 I include Rose and Roja here, who had formerly studied as full-fee paying students in New Zealand.

\section{REFERENCES}

Ang, I. 2003 'I'm a Feminist but.... “Other” Women and Postnational Feminism', in R. Lewis and S. Mills (eds) Feminist Postcolonial Theory: A Reader, New York: Routledge: 190-206.

Brooks, A. 2004 'The Uncertain Configurations of a Politics of Location: The Intersection of Postcolonial, Feminist, and Nationalistic Discourses in Understanding Chinese Diasporic Communities', in R.B.H. Goh and S. Wong (eds) Asian Diasporas: Cultures, Identities, Representations, Hong Kong: Hong Kong University Press: 15-21..

Bullen, E. and J. Kenway 2003 'Real or Imagined Women? Staff Representations of International Women Postgraduate Students', Discourse: Studies in the Cultural Politics of Education, 24 (1):35-50.

Chawla, D. and A. Rodriguez 2007 'New Imaginations of Difference: On Teaching, Writing, and Culturing', Teaching in Higher Education, 12 (5-6): 697-708. 
Collins, F.L. 2006 'Making Asian Students, Making Students Asian: The Racialisation of Export Education in Auckland, New Zealand', Asia Pacific Viewpoint, 47 (2): 217-234.

De Verthelyi, R. F. 1995 'International Students' Spouses: Invisible Sojourners in the Culture Shock Literature', International Journal of Intercultural Relations, $19(3): 387-411$.

Diangelo, R.J. 2006 'The Production of Whiteness in Education: Asian International Students in a College Classroom, Teachers College Record, 108 (10): 1983-2000.

Doane, A. 2006 'What is Racism? Racial Discourse and Racial Politics', Critical Sociology, $32(2-3): 255-274$.

Education New Zealand, 2008 'E-news Special Edition: Generic Promotion Campaigns' http://www.educationnz.org.nz/comm/enews/enz_industry_ 17Aprilo8.html

Fine, M. and L. Weis 2005 'Compositional Studies, In Two Parts: Critical Theorizing and Analysis on Social (In)justice', in N. K. Denzin and Y. S. Lincoln (eds) The Sage Handbook of Qualitative Research (Third Edition), Thousand Oaks, California: Sage: 65-84.

Haigh, M. J. 2002 'Internationalisation of the Curriculum: Designing Inclusive Education for a Small World', Journal of Geography in Higher Education, 26 (1): 49-66.

Hall, S. 1996 'Introduction: Who Needs 'Identity'?', in S. Hall and P. Du Gay (eds) Questions of Cultural Identity, London: Sage: 1-17.

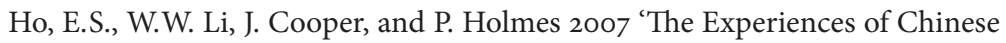
International Students in New Zealand' http://www.educationnz.org.nz/ indust_researchreports.html

Immigration New Zealand, 2007 'Areas of Absolute Skill Shortage’ http://glossary. immigration.govt.nz/Areaofabsoluteskillsshortage.htm

Ippolito, K. 2007 'Promoting Intercultural Learning in a Multicultural University: Ideals and Realities', Teaching in Higher Education, 12 (5-6):749-763. 
Ichimoto, T. 2004 'Ambivalent 'Selves' in Transition: A Case Study of Japanese Women Studying in Australian Universities', Journal of Intercultural Studies, $25(3): 247-69$.

Kenway, J. and E. Bullen 2003 'Self-representations of International Women Postgraduate Students in the Global University "Contact Zone", Gender and Education, 15(1):5-20.

Larner, W. 2003 'Neoliberalism?', Environment and Planning D: Society and Space, 21: 509-512.

Lather, P. 2006 'Paradigm Proliferation as a Good Thing to Think With: Teaching Research in Education as Wild Profusion', International Journal of Qualitative Studies in Education, 19 (1):35-57.

Lugones, M. 1987 'Playfulness, “World”-Travelling, and Loving Perception', Hypatia, $2(2): 3-19$.

Madge, C., P. Raghuram, and P. Noxolo (in press) 'Engaged Pedagogy and Responsibility: A Postcolonial Analysis of International Students', Geoforum.

Ministry of Education, 2007 The International Education Agenda: A Strategy for 2007-2012, Wellington: Ministry of Education.

Ministry of Education 2008, 'Domestic Student in the Tertiary Sector' http://www. minedu.govt.nz/educationSectors/InternationalEducation/ForProvidersOfInternationalEducation/DefinitionOfDomesticStudent.aspx

Palumbo-Liu, D. 2002 'Assumed Identities', New Literary History, 31: 765-78o.

Robertson, S.L. 2006 'Absences and Imaginings: The Production of Knowledge on Globalisation and Education, Globalisation, Societies and Education, $4(2): 303-318$.

Ward, C. 2006 International Students: Interpersonal, Institutional and Community Impacts. Update of the 2001 Literature Review, Wellington: Ministry of Education:

Ward, C. and A.M. Masgoret 2004 The Experiences of International Students in New Zealand, Wellington: Ministry of Education. 